\title{
Comparison of the Incidence of Intra-operative Fractures in Hip Hemi-arthroplasty Performed in Supine and Lateral Positions
}

\author{
Kenta Kamo, MD, Hidehiko Kido, MD, Satoshi Kido, MD \\ Department of Orthopedic Surgery, Yamaguchi Red Cross Hospital, Yamaguchi, Japan
}

Purpose: The difficulty of femoral preparation with supine-position hip hemi-arthroplasty (HA) often leads to intra-operative fractures (IOFs). We aimed to clarify the incidence and types of IOFs in HA for hip fractures performed in the supine and lateral positions.

Materials and Methods: We retrospectively investigated cases of HA for acute femoral neck fractures from June 2013 to May 2018. We examined the incidence and types of IOFs according to different approaches. We defined supine-position in HA as the supine and hip-hyperextended (over-range) femoral preparation position, and lateral position as the lateral and hip-flexed femoral preparation position. We used a short tapered wedged stem.

Results: Supine-position HA was used in 46 patients (23.7\%) and lateral-position HA in 148 patients (76.3\%). IOFs in supine-position HA occurred in 8 patients $(17.4 \%)$ and included five Vancouver $\mathrm{A}_{\mathrm{GT}}$ and three Vancouver B2 fractures. IOFs in lateral-position HA occurred in 3 patients (2.0\%) and included one Vancouver $\mathrm{A}_{\mathrm{GT}}$ and two Vancouver B fractures. Supine-position HA was a risk factor for IOFs (adjusted odds ratio, 9.71; 95\% confidence interval, 2.37-39.8; $P<0.01$ )

Conclusion: Supine-position in HA is an IOF risk factor and significantly increases the incidence of great trochanter fractures of Vancouver type A.

Key Words: Hip replacement arthroplasty, Periprosthetic fractures, Femoral neck fractures, Superior approach, Minimally invasive surgical procedures

Submitted: September 4, 2018 1st revision: December 1, 2018 2nd revision: December 26, 2018 3rd revision: January 8, 2019 Final acceptance: January 8, 2019

Address reprint request to

Kenta Kamo, MD

(https://orcid.org/0000-0003-1008-6517)

Department of Orthopaedic Surgery, Yamaguchi Red Cross

Hospital, 53-1 Yahatababa, Yamaguchi 753-8519, Japan

TEL: +81-083-923-0111 FAX: +81-083-925-1474

E-mail: kamoknts@gaea.ocn.ne.jp

This is an Open Access article distributed under the terms of the Creative Commons Attribution Non-Commercial License (http://creativecommons. org/licenses/by-nc/4.0) which permits unrestricted non-commercial use, distribution, and reproduction in any medium, provided the original work is properly cited.

\section{INTRODUCTION}

In clinical practice, post-operative dislocations after hip hemi-arthroplasty (HA) receive much attention, but intraoperative fractures (IOFs) are often overlooked. The risk factors of IOFs include female sex, increasing age, osteoporosis, rheumatoid arthritis, bone morphology, and cementless stem $^{1-6)}$. Supine-position HA with the anterolateral approach in the supine position (ALS) or direct anterior approach (DAA) has become prevalent. The difficulty of femoral preparations when using ALS or DAA often leads to $\mathrm{IOFs}^{7-10)}$. We also experienced some IOFs and stem mal-alignment in supine-position HA for hip fractures. Before using the supine-position approach, 
we had performed HA with the conventional posterior approach (PA) and experienced IOFs in $3.1 \%$ of the patients (4/128) and dislocations in 2.3\% (3/128) over 5 years. All four IOFs were periprosthetic fractures requiring cerclage wiring. In contrast, supine-position HA caused IOFs of another type (great trochanter fractures) that we had never experienced when using PA. Based on this experience, we had returned to lateralposition HA (PA and superior approach $\left.[\mathrm{SA}]^{11}\right)$, until we took measures to reduce the incidence of IOFs the supine-position HA. No studies have focused on the incidence of IOFs in supine-position and lateral-position HA. We aimed to clarify the incidence and types of IOFs in HA with the supine and lateral positions.

\section{MATERIALS AND METHODS}

We retrospectively investigated cases of HA for acute femoral neck fractures from June 2013 to May 2018. Since June 2013, we had used mainly tapered-wedge stem implants. We collated data regarding the approaches used, operation duration, intra-operative blood loss, and the following complications: IOFs (we used Vancouver classification $\left.^{6}\right)$, treatment for IOFs, post-operative dislocations, deep infections, symptomatic deep venous thrombosis, cerebrovascular infarction, and death. In addition, data on patient characteristics (age at operation, sex, body height, body weight, and body mass index $[\mathrm{BMI}]$ ) and radiographic indices (limb length discrepancy [LLD] and varus angle), healthy (contralateral) center-edge angle, and canal flare index (CFI). This research was approved by the ethics review board of the authors' affiliated institution (H27-11) and written informed consents from the patients were obtained.

\section{Surgery}

We categorized ALS and DAA as supine-position HA because of the supine position and hip hyperextended position in femoral preparation (Table $1^{12-20}$ ). Lateralposition HA was defined as HA using a direct lateral approach (DLA), PA, or SA because of the lateral position and hip-flexed position in femoral preparation (Table 1). In procedures using DAA, we used a standard surgical table. In procedures using DLA, we used a pullout technique to repair the attachments of the gluteus medius and minimus. In procedures using PA, the short rotators and posterior capsule were repaired. In procedures

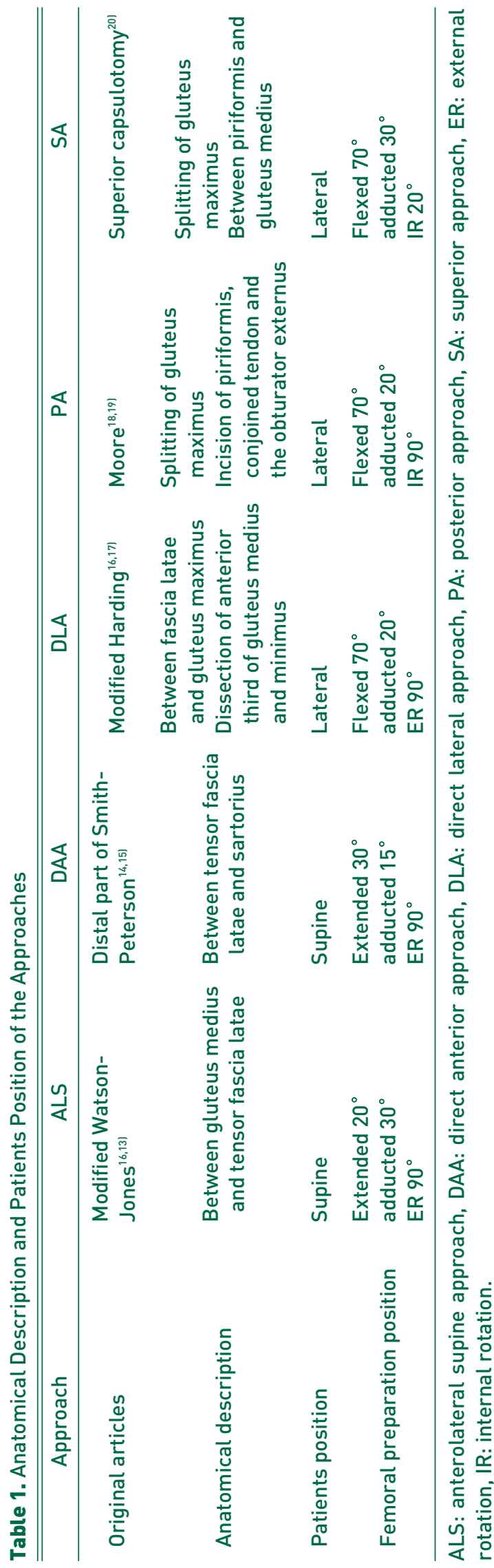




\section{Hip \& Pelvis}

Kenta Kamo et al. Comparison of the Incidence of Intra-operative Fractures in Hip Hemi-arthroplasty Performed

using SA, we preserved the short rotator muscles and used a Dual cup (Kyocera, Kyoto, Japan). This cup makes it possible to attach the outer and inner heads to the acetabular fossa. In addition, we used a trial outer head with a groove to facilitate trial reduction (Fig. 1). Flat broaches enabled neck osteotomy leaving the broach in place untill implantation.

\section{Implants}

We used a short tapered wedged stem (J-Taper Total Hip System) and a bipolar outer head (PHYSIO-HIP SYSTEM ceramic or metal; both from Kyocera). This system does not require reaming of the femur. Since September 2015, we used a snap-in type outer head (KMAX Dual cup CLDCS; Kyocera) for all cases.

\section{Choice of Approach}

Our education system of orthopedic surgeons uses an internship of 6 years. We defined young surgeons as those whose career as orthopedic surgeons was under 6 years. They performed HA with PA as the first approach. Therefore, the surgeons had first mastered PA and then employed other approaches according to their preference.

\section{Statistics}

One-way ANOVA (Bonferroni correction) and the $t$ test were used to compare the operation duration, intraoperative blood loss, and radiographic evaluations using
R 3.0.3 (R Foundation for Statistical Computing, Vienna, Austria). Fisher test was used to analyze categorical data. Multivariable logistic regression was performed to test the correlation between IOFs, Vancouver $A_{\mathrm{GT}}$ type fractures $\left(\mathrm{VA}_{\mathrm{GT}}\right)$, Vancouver $\mathrm{B}$ type fractures $(\mathrm{VB})$, the factors investigated in the previous study ${ }^{1-5)}$ (age, BMI, gender, and CFI), and the variables that showed significant correlation with patient's position $(P<0.05)$.

\section{RESULTS}

This study included 194 patients. The mean age at HA was $82.6 \pm 8.4$ years (Table 2). The number of female patients was 148 (76.3\%). The mean BMI was $20.3 \pm 3.6$ $\mathrm{kg} / \mathrm{m}^{2}$. ALS was used in $25(12.9 \%)$ patients, DAA in 21 (10.8\%), DLA in 9 (4.6\%), PA in 50 (25.8\%), and SA in $89(45.9 \%)$ patients. Young surgeons performed 142 HAs $(73.2 \%)$. The mean operation duration was $66.2 \pm$ 21.7 minutes and the mean operative blood loss was $140.3 \pm 133.2 \mathrm{~g}$. IOFs occurred in $11(5.7 \%)$ patients: six $\mathrm{VA}_{\mathrm{GT}}$ fractures, one VB1, and four VB2. IOFs occurred in $4.2 \%(6 / 142)$ of young surgeons' HAs and 9.6\% $(5 / 52)$ of experienced surgeons' HAs $(P=0.17)$.

In the radiographic analysis, we excluded four IOFs (conversion to a cement stem), five straight stems, and one planned cement stem. The 184 patients for whom a tapered-wedge stem was used were evaluated by postoperative radiographs. The mean LLD was $3.2 \pm 5.5 \mathrm{~mm}$ and the mean varus angle was $0.1 \pm 1.6^{\circ}$. We excluded three hip arthroplasties and three multiple pinnings. The radiographic indices on the healthy side for the patients
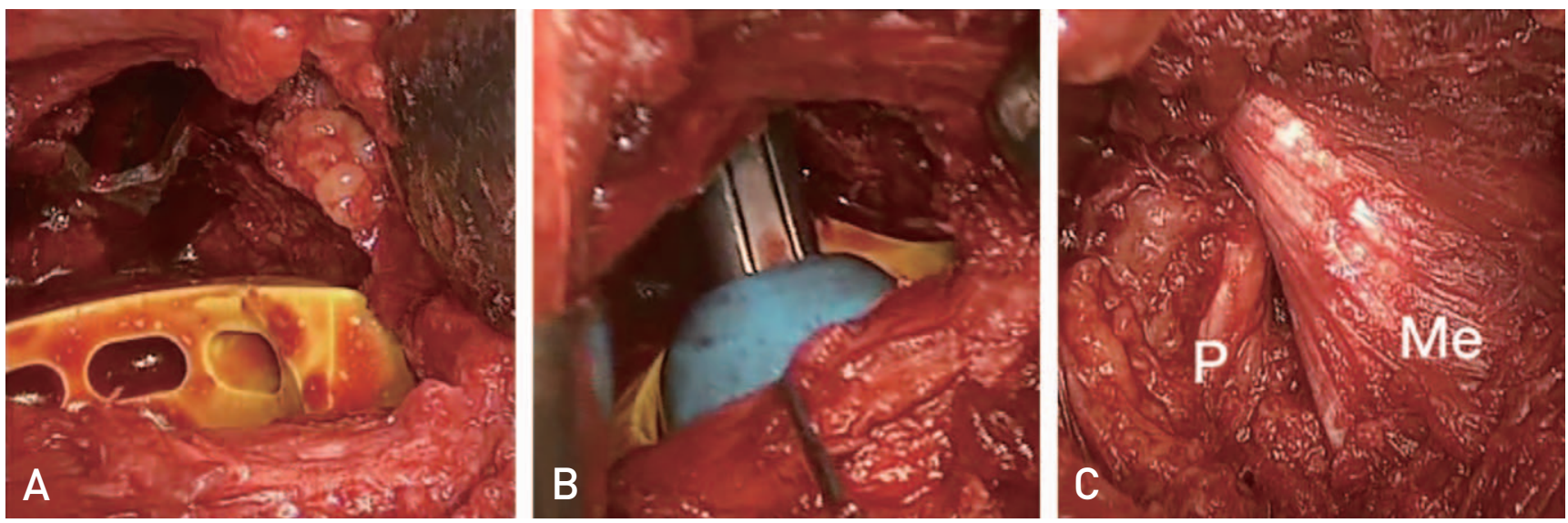

Fig. 1. (A) The trial outer head with groove to minimize difficulty in trial reduction. The flat broaches made the neck osteotomy possible leaving the broach in place. (B) Trial reduction on the left hip hemi-arthroplasty. The piriformis was retracted posteriorly and the gluteus medius was retracted anteriorly. (C) The piriformis (P) and the gluteus medius (Me) were preserved after implantation. 


\section{Hip \& Pelvis}

Hip Pelvis 31(1): 33-39, 2019

$(\mathrm{n}=188)$ were as follows: mean center-edge angle was $31.5 \pm 6.5^{\circ}$, mean CFI was $3.6 \pm 0.6$.

\section{Comparison between Approaches}

IOFs occurred in supine-position HAs in $8(17.4 \%)$ patients and in lateral-position HAs in $3(2.0 \%)$ patients (Table 3, 4). With ALS, IOFs occurred in 4 (16.0\%) patients; three IOFs were VB2 fractures and required conversion from a taper wedged stem to a cement stem, and another IOF was a $\mathrm{VA}_{\mathrm{GT}}$ fracture, which required a claw plate. With DAA, IOFs occurred in 4 (19.0\%) patients; all four cases were $\mathrm{VA}_{\mathrm{GT}}$ fracture and required no specific treatment. With PA, IOFs occurred in 2 (4.0\%) patients: a VB2 fracture required cerclage wiring and a $\mathrm{VA}_{\mathrm{GT}}$ fracture required tension band wiring and conversion to a cement stem. With SA, IOFs occurred in $1(1.1 \%)$ patient: VB1 was diagnosed on a postoperative radiograph and required non-weight bearing for 6 weeks.

\section{The Risk Factor of IOFs}

Multivariable logistic regression analysis revealed that supine-position HA was a risk factor for IOFs (adjusted odds ratio [OR], 9.71; 95\% confidence interval [CI],

Table 2. Patient Characteristics, Surgical Parameters, Radiographic Indices, and Complications

\begin{tabular}{|c|c|c|}
\hline Variable & Data & $P$-value \\
\hline Patient characteristic & $194(148 / 46)$ & \\
\hline Age (yr) & $82.6 \pm 8.4(83.0 \pm 8.4 / 81.5 \pm 8.3)$ & 0.3 \\
\hline Height $(\mathrm{cm})$ & $152.9 \pm 8.5(149.7 \pm 5.6 / 163.6 \pm 7.9)$ & $<0.01$ \\
\hline Weight (kg) & $47.9 \pm 10.3(45.3 \pm 8.8 / 56.4 \pm 10.7)$ & $<0.01$ \\
\hline Body mass index $\left(\mathrm{kg} / \mathrm{m}^{2}\right)$ & $20.3 \pm 3.6(20.1 \pm 3.5 / 20.9 \pm 3.9)$ & 0.2 \\
\hline \multicolumn{3}{|l|}{ Surgical parameter } \\
\hline \multicolumn{3}{|l|}{ Approaches } \\
\hline Supine-position & $46(23.7)$ & \\
\hline Lateral-position & $148(76.3)$ & \\
\hline Young surgeons' hemi-arthroplasty & $142(73.2)$ & \\
\hline Operation duration (min) & $66.2 \pm 21.7(64.8 \pm 21.4 / 70.8 \pm 22.2)$ & 0.1 \\
\hline Blood loss $(\mathrm{g})$ & $140.3 \pm 133.2(131.9 \pm 123.1 / 167.6 \pm 160.4)$ & 0.1 \\
\hline LLD $(\mathrm{mm})$ & $3.2 \pm 5.5(3.7 \pm 5.4 / 1.9 \pm 5.6)$ & 0.06 \\
\hline Varus $\left({ }^{\circ}\right)$ & $0.1 \pm 1.6[0.1 \pm 1.5 / 0.1 \pm 1.9]$ & 0.9 \\
\hline \multicolumn{3}{|l|}{ Implants } \\
\hline J-Taper & $184(94.8)$ & \\
\hline J-Taper to cement stem & $4(2.1)$ & \\
\hline Others & $6(3.1)$ & \\
\hline \multicolumn{3}{|l|}{ Radiographic indices ( $n=188$ ) } \\
\hline Center-edge angle $\left({ }^{\circ}\right)$ & $31.5 \pm 6.5(31.2 \pm 6.4 / 32.2 \pm 6.7)$ & 0.4 \\
\hline Canal flare index & $3.6 \pm 0.6(3.5 \pm 0.7 / 3.6 \pm 0.6)$ & 0.4 \\
\hline \multicolumn{3}{|l|}{ Complications } \\
\hline Follow-up duration (mo) & $10 \pm 9$ & \\
\hline Patients with complications & $35(18.0)$ & \\
\hline Intra-operative fractures & $11(5.7)$ & 0.17 \\
\hline Young surgeon (n=142) & $6(4.2)$ & \\
\hline Experienced (n=52) & $5(9.6)$ & \\
\hline Post-operative fractures & $6(3.1)$ & \\
\hline Contralateral fractures & $6(3.1)$ & \\
\hline Death & $6(3.1)$ & \\
\hline Cerebrovascular infarctions & $5(2.6)$ & \\
\hline Dislocations & $3(1.5)$ & \\
\hline sDVT & $1(0.5)$ & \\
\hline Deep infections & $0(0)$ & \\
\hline
\end{tabular}

Values are presented as number only (female/male), mean \pm standard deviation (female/male), or number (\%). LLD: limb length discrepancy, sDVT: symptomatic deep venous thrombosis. 
Kenta Kamo et al. Comparison of the Incidence of Intra-operative Fractures in Hip Hemi-arthroplasty Performed

2.37-39.8; $P<0.01$ ) and $\mathrm{VA}_{\mathrm{GT}}$ fractures (adjusted $\mathrm{OR}$, $15.1 ; 95 \%$ CI, 1.68-136; $P=0.02$ ) (Table 5-7).

\section{DISCUSSION}

In our study, IOFs occurred in $5.7 \%$ of the patients, which was higher than the frequency of post-operative dislocations $(1.6 \%)$. IOFs were frequently (in $17.4 \%$ of the cases) encountered with the use of supine-position $\mathrm{HA}$, this rate was higher than that with lateral-position HA $(2.0 \%)$. IOFs were not related to surgical experience, in line with the previous studies ${ }^{1,8}$.

In ALS, the difficulty of implant insertion causes femoral shaft penetration $(0.3 \%)$. In our patients, three
VB2 fractures occurred during rasping or implantation. One $\mathrm{VA}_{\mathrm{GT}}$ occurred during elevation of the femur. In DAA, fractures of the great trochanter occur at a frequency of $1.4 \%$ to $4.5 \% \%^{9,21,22}$. An insufficient release of the capsule ${ }^{9)}$ and elevation of the femur with powerful levers ${ }^{10)}$ result in great trochanter fractures. Additionally, the reduction maneuver results in periprosthetic fractures ${ }^{4}$. In our patients, all four $\mathrm{VA}_{\mathrm{GT}}$ fractures were diagnosed on post-operative radiographs. In DLA, $\mathrm{VA}_{\mathrm{GT}}$ occurs at a frequency of $0.7 \%$ to $3 \%, \mathrm{VA}_{\mathrm{LT}}$ at $2.8 \%$ to $8.1 \%$, and VB fractures at $6.4 \%{ }^{1,23}$. These two reports did not mention whether some particular procedures of DLA cause these fractures. Generally, VB fractures occur because of a mismatch between the stem and

Table 3. Comparison between the Approaches

\begin{tabular}{|c|c|c|c|c|c|c|}
\hline Variable & ALS (n=25) & DAA $(n=21)$ & DLA (n=9) & $P A(n=50)$ & SA (n=89) & $P$-value \\
\hline Age (yr) & $82.2 \pm 8.7$ & $83.0 \pm 7.7$ & $87.1 \pm 6.6$ & $83.6 \pm 6.7$ & $81.7 \pm 9.4$ & 0.4 \\
\hline $\mathrm{BMI}\left(\mathrm{kg} / \mathrm{m}^{2}\right)$ & $20.7 \pm 3.3$ & $20.2 \pm 3.6$ & $21.4 \pm 4.1$ & $20.6 \pm 3.4$ & $19.9 \pm 3.7$ & 0.7 \\
\hline Young surgeon & $15(60.0)$ & $14(66.7)$ & $7(77.8)$ & $45(90.0)$ & $61(68.5)$ & $<0.05$ \\
\hline Operation duration (min) & $80 \pm 33$ & $63 \pm 14$ & $82 \pm 28$ & $72 \pm 20$ & $58 \pm 15$ & $<0.01$ \\
\hline Blood loss $(g)$ & $222 \pm 225$ & $202 \pm 174$ & $128 \pm 9$ & $107 \pm 108$ & $123 \pm 87$ & $<0.01$ \\
\hline LLD (mm) & $6.5 \pm 4.8$ & $4.3 \pm 6.1$ & $0.4 \pm 7.6$ & $4.1 \pm 4.3$ & $2.1 \pm 5.4$ & $<0.01$ \\
\hline Varus angle $\left({ }^{\circ}\right)$ & $1.5 \pm 1.8$ & $0.0 \pm 2.2$ & $1.1 \pm 2.0$ & $-0.2 \pm 1.0$ & $-0.1 \pm 1.4$ & $<0.01$ \\
\hline \multicolumn{7}{|l|}{ Implants } \\
\hline J-taper & $19(76.0)$ & $21(100)$ & $9(100)$ & $46(92.0)$ & $89(100)$ & $<0.01$ \\
\hline J-taper to cement stem & $3(12.0)$ & $0(0)$ & $0(0)$ & $1(2.0)$ & $0(0)$ & \\
\hline Straight stem & $3(12)$ & $0(0)$ & $0(0)$ & $2(4.0)$ & $0(0)$ & \\
\hline Cement & $0(0)$ & $0(0)$ & $0(0)$ & $1(2.0)$ & 0 & \\
\hline Intra-operative fractures & $4(16.0)$ & $4(19.0)$ & $0(0)$ & $2(4.0)$ & $1(1.0)$ & $<0.01$ \\
\hline Vancouver $A_{G T}$ & $1(4.0)$ & $4(19.0)$ & $0(0)$ & $1(2.0)$ & $0(0)$ & \\
\hline Vancouver B1 & $0(0)$ & $0(0)$ & $0(0)$ & $0(0)$ & $1(1.0)$ & \\
\hline Vancouver B2 & $3(12.0)$ & $0(0)$ & $0(0)$ & $1(4.0)$ & $0(0)$ & \\
\hline Young surgeon & $\begin{array}{l}\mathrm{VA}_{\mathrm{GT}}, 1 / \\
\mathrm{VB} 2,1\end{array}$ & $\mathrm{VA}_{\mathrm{GT}}, 2$ & $0(0)$ & $\begin{array}{l}\mathrm{VA}_{\mathrm{GT}}, 1 / \\
\mathrm{VB} 2,1\end{array}$ & $0(0)$ & 0.56 \\
\hline Dislocations & $2(8.0)$ & $0(0)$ & $0(0)$ & $1(2.0)$ & $0(0)$ & 0.07 \\
\hline
\end{tabular}

Values are presented as mean \pm standard deviation or number $(\%)$.

ALS: anterolateral supine approach, DAA: direct anterior approach, DLA: direct lateral approach, PA: posterior approach, SA: superior approach, BMI: body mass index, LLD: limb length discrepancy, HA: hemi-arthroplasty.

Table 4. Comparison between the Supine and Lateral-position Approach

\begin{tabular}{lccc}
\hline \hline Variable & Supine-position HAs $(\mathrm{n}=46,23.7 \%)$ & Lateral-position HAs $(\mathrm{n}=148,76.3 \%)$ & $P$-value \\
\hline Operation duration (min) & $72.4 \pm 27.5$ & $64.3 \pm 19.2$ & $118 \pm 93$ \\
Blood loss (g) & $213 \pm 201$ & $2.6 \pm 5.3$ & $<0.05$ \\
LLD (mm) & $5.3 \pm 5.5$ & $0 \pm 1.3$ & $<0.01$ \\
Varus angle $\left({ }^{\circ}\right)$ & $0.7 \pm 2.1$ & $3(2.0)$ & $<0.01$ \\
Intra-operative fractures & $8(17.4)$ & $1(0.7)$ & $<0.01$ \\
Dislocations & $2(4.3)$ & 0.14 \\
\hline
\end{tabular}

Values are presented as mean \pm standard deviation or number $(\%)$.

HA: hemi-arthroplasty, LLD: limb length discrepancy. 
canal during rasping in an osteoporotic femur ${ }^{24}$. In PA, periprosthetic fractures occur at a frequency of $1.8 \%$ to $2.6 \%{ }^{21,22)}$. In our cases, one VB2 fracture occurred during final stem insertion and one $\mathrm{VA}_{\mathrm{GT}}$ occurred during removal of the rasp. In SA, periprosthetic fractures occur at a frequency of $5.8 \%{ }^{14}$. In our cases, one VB1 fracture was diagnosed on a radiograph at 1 week postoperatively. Theoretically, rasping before the neck cut would reduce hoop stress and prevent VB fractures ${ }^{14)}$.

We thought that the hyperextended (over-range) position of the femoral rasping and soft tissue sparing would overload the tip of the great trochanter and the proximal femur in the supine position. Insufficient release of the hip capsule would result in excessive leverage momentum of the retractor behind the greater trochanter during hip extension, which may lead to $\mathrm{VA}_{\mathrm{GT}}$. It would also lead to an oblique fracture of the proximal femur due to excessive external rotation torque applied to the distal femur to maintain the hip at the desired position to insert the stem. Lastly, an insufficient release of the capsule would lead to penetration of the femur by the femoral stem. In ALS and DAA, a release of the capsule and short external rotators as necessary would prevent IOFs and facilitate femoral preparation. The femoral preparation positions over a normal range of motion would require a release of muscles and the hip capsule. Fewer complications and correct implantation should precede muscle sparing.

Several limitations of this study should be acknowledged. First, this study was a retrospective case series. Second, we did not evaluate bone quality and disease-specific osteoporosis-like rheumatoid arthritis and further studies should be required. In our hospital (500-bed, secondary-

Table 5. The Risk Factors of Intra-operative Fracture

\begin{tabular}{|c|c|c|c|c|c|c|}
\hline \multirow{2}{*}{ Factor } & \multicolumn{3}{|c|}{ Unadjusted } & \multicolumn{3}{|c|}{ Adjusted } \\
\hline & OR & $95 \% \mathrm{Cl}$ & $P$-value & OR & $95 \% \mathrm{Cl}$ & $P$-value \\
\hline Age & 1.06 & $0.97-1.16$ & 0.17 & 1.06 & $0.97-1.16$ & 0.19 \\
\hline BMI & 0.98 & $0.82-1.17$ & 0.83 & 0.99 & $0.81-1.21$ & 0.92 \\
\hline $\mathrm{CFI}$ & 0.5 & $0.18-1.42$ & 0.19 & 0.72 & $0.21-2.46$ & 0.61 \\
\hline Male & 0.7 & $0.15-3.37$ & 0.66 & 1.03 & $0.19-5.56$ & 0.97 \\
\hline Supine-position & 10.2 & $2.58-40.2$ & $<0.01$ & 9.71 & $2.37-39.8$ & $<0.01$ \\
\hline
\end{tabular}

OR: odds ratio, $\mathrm{Cl}$ : confidence interval, $\mathrm{BMI}$ : body mass index, $\mathrm{CFI}$ : canal flare index.

Table 6. The Risk Factors of Intra-operative Vancouver $A_{G T}$ Fracture

\begin{tabular}{|c|c|c|c|c|c|c|}
\hline \multirow{2}{*}{ Factor } & \multicolumn{3}{|c|}{ Unadjusted } & \multicolumn{3}{|c|}{ Adjusted } \\
\hline & OR & $95 \% \mathrm{Cl}$ & $P$-value & OR & $95 \% \mathrm{Cl}$ & $P$-value \\
\hline Age & 1.01 & $0.91-1.11$ & 0.9 & 0.99 & $0.89-1.11$ & 0.9 \\
\hline BMI & 1.01 & $0.81-1.27$ & 0.9 & 1.0 & $0.78-1.28$ & 0.99 \\
\hline CFI & 0.321 & $0.07-1.41$ & 0.133 & 0.36 & $0.64-1.99$ & 0.2 \\
\hline Male & 0.636 & $0.07-5.58$ & 0.7 & 1.0 & $0.1-9.9$ & 0.99 \\
\hline Supine-position & 17.9 & $2.04-158$ & $<0.01$ & 15.1 & $1.68-136$ & 0.02 \\
\hline
\end{tabular}

OR: odds ratio, $\mathrm{Cl}$ : confidence interval, $\mathrm{BMI}$ : body mass index, $\mathrm{CFI}$ : canal flare index.

Table 7. The Risk Factors of Intra-operative Vancouver B Fracture

\begin{tabular}{|c|c|c|c|c|c|c|}
\hline \multirow{2}{*}{ Factor } & \multicolumn{3}{|c|}{ Unadjusted } & \multicolumn{3}{|c|}{ Adjusted } \\
\hline & OR & $95 \% \mathrm{Cl}$ & $P$-value & OR & $95 \% \mathrm{Cl}$ & $P$-value \\
\hline Age & 1.15 & $0.99-1.34$ & 0.07 & 1.16 & $0.98-1.37$ & 0.07 \\
\hline BMI & 0.939 & $0.72-1.23$ & 0.6 & 0.954 & $0.69-1.3$ & 0.77 \\
\hline CFI & 0.836 & $0.20-3.45$ & 0.8 & 1.71 & $0.30-9.65$ & 0.5 \\
\hline Male & 0.8 & $0.09-7.34$ & 0.8 & 1.18 & $0.12-12.1$ & 0.89 \\
\hline Supine-position & 5.09 & $0.82-31.5$ & 0.08 & 5.91 & $0.86-40.6$ & 0.07 \\
\hline
\end{tabular}

OR: odds ratio, $\mathrm{Cl}$ : confidence interval, $\mathrm{BMI}$ : body mass index, $\mathrm{CFI}$ : canal flare index. 
Kenta Kamo et al. Comparison of the Incidence of Intra-operative Fractures in Hip Hemi-arthroplasty Performed

level), lateral-position HAs decreased the incidence of IOFs. Meanwhile, the incidence of post-operative dislocations remained low. The post-operative LLD and varus angle of lateral-position HAs were more favorable than those of supine-position HAs. These results may be useful for young and experienced surgeons to employ new or unused approaches.

\section{CONCLUSION}

The supine position in HA surgery is an IOF risk factor and significantly increases the incidence of great trochanter fractures of Vancouver type A.

\section{CONFLICT OF INTEREST}

Kenta Kamo has received consulting fees from Kyocera. The authors declare that there is no potential conflict of interest relevant to this article.

\section{REFERENCES}

1. Aslam-Pervez N, Riaz O, Gopal S, Hossain F. Predictors of intraoperative fractures during hemiarthroplasty for the treatment of fragility hip fractures. Clin Orthop Surg. 2018;10:14-9.

2. Duncan CP, Masri BA. Fractures of the femur after hip replacement. Instr Course Lect. 1995;44:293-304.

3. Davidson D, Pike J, Garbuz D, Duncan CP, Masri BA. Intraoperative periprosthetic fractures during total hip arthroplasty. Evaluation and management. J Bone Joint Surg Am. 2008;90:2000-12.

4. Cooper HJ, Rodriguez JA. Early post-operative periprosthetic femur fracture in the presence of a non-cemented tapered wedge femoral stem. HSS J. 2010;6:150-4.

5. Miettinen SS, Mäkinen TJ, Kostensalo I, et al. Risk factors for intraoperative calcar fracture in cementless total hip arthroplasty. Acta Orthop. 2016;87:113-9.

6. van der Sijp MPL, van Delft D, Krijnen P, Niggebrugge AHP, Schipper IB. Surgical approaches and hemiarthroplasty outcomes for femoral neck fractures: a meta-analysis. J Arthroplasty. 2018;33:1617-27.e9.

7. van den Bekerom MP, Sierevelt IN, Bonke H, Raaymakers EL. The natural history of the hemiarthroplasty for displaced intracapsular femoral neck fractures. Acta Orthop. 2013;84:555-60.

8. Schneider K, Audigé L, Kuehnel SP, Helmy N. The direct anterior approach in hemiarthroplasty for displaced femoral neck fractures. Int Orthop. 2012;36:1773-81.

9. Baba T, Shitoto K, Kaneko K. Bipolar hemiarthroplasty for femoral neck fracture using the direct anterior approach. World J Orthop. 2013;4:85-9.

10. Unger AC, Dirksen B, Renken FG, Wilde E, Willkomm M, Schulz AP. Treatment of femoral neck fracture with a minimal invasive surgical approach for hemiarthroplasty clinical and radiological results in 180 geriatric patients. Open Orthop J. 2014;8:225-31.

11. Kamo K, Kido H, Kido S, et al. [The concept of the superior approach for hip arthroplasty]. Jpn J Joint Dis. 2017:36: 457-60. Japanese.

12. Higuchi F, Gotoh M, Yamaguchi N, et al. Minimally invasive uncemented total hip arthroplasty through an anterolateral approach with a shorter skin incision. J Orthop Sci. 2003;8:812-7.

13. Moore AT. The self-locking metal hip prosthesis. J Bone Joint Surg Am. 1957;39-A:811-27.

14. Nakamura S, Matsuda K, Arai N, Wakimoto N, Matsushita T. Mini-incision posterior approach for total hip arthroplasty. Int Orthop. 2004;28:214-7.

15. Murphy SB, Ecker TM, Tannast M. THA performed using conventional and navigated tissue-preserving techniques. Clin Orthop Relat Res. 2006;453:160-7.

16. Tsukada S, Wakui M. Minimally invasive intermuscular approach does not improve outcomes in bipolar hemiarthroplasty for femoral neck fracture. J Orthop Sci. 2010;15:753-7.

17. Pala E, Trono M, Bitonti A, Lucidi G. Hip hemiarthroplasty for femur neck fractures: minimally invasive direct anterior approach versus postero-lateral approach. Eur J Orthop Surg Traumatol. 2016;26:423-7.

18. Bodrogi AW, Sciortino R, Fitch DA, Gofton W. Use of the supercapsular percutaneously assisted total hip approach for femoral neck fractures: surgical technique and case series. J Orthop Surg Res. 2016;11:113.

19. Chana R, Mansouri R, Jack C, et al. The suitability of an uncemented hydroxyapatite coated (HAC) hip hemiarthroplasty stem for intra-capsular femoral neck fractures in osteoporotic elderly patients: the Metaphyseal-Diaphyseal Index, a solution to preventing intra-operative periprosthetic fracture. J Orthop Surg Res. 2011;6:59.

20. Bertin KC, Röttinger H. Anterolateral mini-incision hip replacement surgery: a modified Watson-Jones approach. Clin Orthop Relat Res. 2004;(429):248-55.

21.Pflüger G, Junk-Jantsch S, Schöll V. Minimally invasive total hip replacement via the anterolateral approach in the supine position. Int Orthop. 2007;31 Suppl 1:S7-11.

22. Smith-Petersen MN. Approach to and exposure of the hip joint for mold arthroplasty. J Bone Joint Surg Am. 1949; 31A:40-6.

23. Siguier T, Siguier M, Brumpt B. Mini-incision anterior approach does not increase dislocation rate: a study of 1037 total hip replacements. Clin Orthop Relat Res. 2004; (426):164-73.

24. Hardinge K. The direct lateral approach to the hip. J Bone Joint Surg Br. 1982;64:17-9. 